\title{
Para una tipología del exilio literario sudeslavo
}

\author{
Francisco Javier JuEZ GÁLVEZ \\ Departamento de Filología Románica, Filología Eslava y Lingüística General \\ Universidad Complutense de Madrid \\ juezgalvez@filol.ucm.es
}

\section{RESUMEN}

En la amplia dimensión cronológica y geográfica de las literaturas eslavas meridionales, el estudio del exilio literario plantea una serie de cuestiones preliminares relacionadas con el concepto de Slavia Ortodoxa y la dispersión de los miembros de la Escuela Literaria de Tarnovo en 1393, la literatura reformada eslovena y croata de la segunda mitad del siglo XVI, las actividades fuera de los confines del (futuro) Exarcado de Bulgaria de los literatos del "Renacimiento Nacional" (esp. 1820-1870) con motivaciones revolucionarias o formativas, y en el período más fructífero, el siglo XX, con las oleadas de emigración económica, principalmente a las Américas, el exilio motivado por la II Guerra Mundial, en su transcurso o después de ella, que es europeo y americano, las crisis de los sesenta, la caída del muro de Berlín o las guerras yugoslavas y sus consecuencias literarias, pero también lingüísticas.

Palabras clave: literaturas sudeslavas, exilio literario, migración de lengua.

\section{Towards a Typology of South Slavonic Literary Exile}

\begin{abstract}
In the broad chronological and geographical dimension of South Slavic literatures, the study of literary exile raises a number of preliminary issues related to the concept of Slavia Orthodoxa and the dispersal of the Tãrnovo Literary School's members in 1393, the reformed Slovenian and Croatian literature in the second half of the sixteenth century, the activities outside the borders of the (future) Exarchate of the Bulgarian Renaissance writers (esp. 18201870), revolutionary motivated or in education, and the most fruitful period, the twentieth century, with waves of economic migration, mostly to the Americas, the exile provoked by the Second World War, during it or after it, which is European and American, the crisis of the '60s, the fall of the Berlin Wall (1989) or the Yugoslav wars and their literary and also language consequences.
\end{abstract}

Key words: South Slavonic literatures, literary exile, language migration. 


\section{INTRODUCCIÓN}

Aunque la propia España ha sido receptora de emigrantes y exilados, con una notable presencia eslava y europea oriental en general en los años que siguieron a la II Guerra Mundial (1939-1945), la bibliografía española sólo parece reconocer bajo la combinación de los lemas "exilio" y "literatura" la literatura española en el exilio (republicano) tras la Guerra Civil (1936-1939), los exilios literarios americanos, ya interamericanos, ya hispanoamericano-españoles, y como dato exótico el exilio literario alemán durante el III Reich (1933-1945).

El maestro Claudio Guillén (1924-2007) dedicó en 1995 un largo estudio a la literatura del exilio, en el que, además de introducir la idea "del destierro al destiempo", amplió considerablemente las miras hispánicas respecto a la literatura del exilio, partiendo desde la Antigüedad grecorromana, incorporando al ya tópico Ovidio en los confines bárbaros del Imperio ex Ponto, con lo que nos acercamos geográficamente a nuestro objetivo, pero también a los poetas chinos y los desterrados prerrenacentistas (Petrarca, Dante), Joachim du Bellay o William Shakespeare. Entre los emigrantes y emigrados dedica su atención a varios poetas románticos polacos, especialmente a Adam Mickiewicz (Guillén 1998: 78-81).

En el mundo eslavo meridional del siglo XX, los cataclismos ocasionados por las dos guerras mundiales, el recrudecimiento de los regímenes comunistas en los años sesenta y la caída de éstos a finales de los años ochenta, han creado notables contingentes de emigrantes políticos a países europeos occidentales o americanos, entre los cuales nutridos grupos de literatos que siguieron escribiendo en el exilio, o que emprendieron la carrera literaria fuera de su patria.

Sin embargo, hay otros momentos en siglos anteriores que afectan a una o a varias de las naciones sudeslavas y que pueden ser interpretados como provocadores de posibles exilios o pre-exilios, sean éstos en los siglos XIV o XVII.

\section{EXILIO Y SLAVIA ORTHODOXA}

Convergen en un momento histórico dos fenómenos que han marcado la Edad Moderna de la Europa Oriental: con la irrupción de las hordas otomanas en Europa, o Rumelia, comienza la civilización balcánica, incluso desde un punto de vista nominalista: ellos aportan el término Balkan, y las tierras que portaron su presencia son las hoy conocidas como los Balcanes.

Pero, por otro lado, indirectamente, la invasión otomana provocó la creación de una parte específica, la más homogénea aún hoy, de lo que en palabras de Obolensky conocemos como Byzantine Commonwealth: se trata de la Slavia Orthodoxa, que, como construcción intelectual, proviene de una oleada de literatos que parten al exilio. $\mathrm{Y}$ en el exilio continúan y trastierran su labor.

En 1393, con la caída de la ciudad real de Tằrnovgrad (hoy, Veliko Tằrnovo) en manos de los musulmanes otomanos, los literatos miembros de la llamada "Escuela Literaria de Tằrnovo" ( Търновска книжовна шкома ), discípulos de su fundador, el patriarca Eutimio de Tằrnovo (Патриарх Евтимий Търновски) se dispersan por los paí- 
ses cristianos ortodoxos y contribuyen desde su exilio o sus exilios a la creación o consolidación de sus literaturas respectivas. Son los casos del Metropolitano Cipriano (митрополит Киприан 1336-1406) en Rusia, Grigórij Cámblak Григорий Цамблак, ca. 1365-1420) en Constantinopla, Serbia, Moldo-Valaquia y Rusia, o Constantino de Kóstenec Константин Костенечки, † post 1431) en Serbia, considerados, incluso por la ciencia literaria búlgara, además de literatos búlgaros, búlgaro y ruso; búlgaro, rumano, [serbio] y ruso; y [búlgaro y serbio], respectivamente (Petkánova 2003: $247,129-130,266)$.

\section{PRINCIPIOS ÉXULES DE UNA LITERATURA}

Los comienzos de la literatura eslovena de autor, es decir, la que no se reduce a la creación popular, están ligados a "las ideas del protestantismo" (Janež 1959: 31), que destacaban la necesidad de leer la Biblia y la introducción de la lengua vernácula en los libros litúrgicos.

Así devino Primož Trubar (1508-1586) fundador de la literatura eslovena, gracias a su huida de Ljubljana a Alemania en 1548, donde publicó, en primer lugar, el Abecedarium con un catecismo a finales de 1550, y a principios de 1551 el Catechismus In der Windischenn Sprach, ambos salidos de las prensas de Tubinga, y este último "durch Philopatridum Illiricum", e impreso en "Sybenburgen", ya que en Transilvania los protestantes no estaban perseguidos. A éstos les siguió otra veintena de libros, alguno de ellos en alemán.

La labor religiosa y literaria la continúan sus discípulos Sebastijan Krelj (15381567), autor de la Otrozhia Biblia (Biblia Infantil) en 1566 y Jurij Dalmatin (ca. 1547-1589), que tradujo la Biblia completa, publicada en Wittenberg en 1584 por el impresor Janz Mandelc, el primer editor carniolano, recién expulsado, con el título Biblia, tu ie, vse Svetu Pismu Stariga inu Noviga Testamenta, Slovenski tolmazhena, skusi Juria Dalmatina.

\section{EL PAPEL PECULIAR DE LA LITERATURA REFORMADA CROATA}

Junto a este grupo de escritores protestantes eslovenos encontramos otros correligionarios croatas, característicamente de la región de Istria, que, si no fundadores de su literatura nacional en lengua vernácula, ya cultivada desde el siglo anterior, incluso como "literatura de autor" (recuérdese la Judita maruliana, firmada en 1501), representan la etiquetada como "literatura protestante croata", caracterizada toda ella como una literatura exul en las tierras alemanas, y ligada fundamentalmente a la librería del noble protestante croata exilado Ivan Ungnad (1493-1564) en Urach, en las cercanías de Tubinga, algunas veces denominada "instituto bíblico".

Desde el punto de vista de la evolución literaria, empero, el "grupo istriano" de protestantes croatas: Matija Vlaèiæ Ilirik (1520-1575), Stipan Konzul Istranin (1521-1568) y Antun Dalmatin ( $\uparrow 1579)$, no presupone ninguna ruptura con la tra- 
dición literaria nacional, pues continúan con otros fines, dentro del protestantismo, varias de las líneas de cultivo de la literatura croata.

Los tres son conocidos también por sus nombres latinos, pues se inscriben en el latinismo croata, del que el primero de ellos es representante destacado, presentado en las antologías (Gortan-Vratoviæ 1969: 679-707). Los otros dos continúan y renuevan la tradición glagolítica y cirílica de la literatura religiosa católica y paleoslava (Ježæ 1944: 97-98).

En los tres casos se destaca explícitamente la calidad de desterrados de los protestantes croatas en general y de los literatos en particular: hasta llegan a recibir cognomina al efecto, que indican su origen nacional sudeslavo (Matthias Flacius Illyricus), regional (Stephanus Consul (H)istrianus) y, quizá por llevar como nomen el de su origen familiar (se desconoce su lugar de nacimiento, aunque se aduce la ciudad de Senj), explícitamente el de desterrado: Antonius Dalmata Exul.

\section{EL RENACIMIENTO NACIONAL BÚLGARO EN EL EXILIO}

El Renacimiento Nacional Búlgaro (1762-1878) se caracteriza, precisamente, por acontecer en el período anterior a la restauración definitiva de la estatalidad búlgara. Es el período de formación de la literatura búlgara en su fase premoderna, anterior a la incorporación plena de esa literatura ortodoxa a las corrientes literarias europeas.

¿Cómo puede hablarse, en esas circunstancias, de exilio literario, o exilio en general? Racionalizaciones a posteriori aparte, son los propios autores los que se definen en el exilio, no sólo los estudiosos contemporáneos.

1. En la historiografía literaria del Renacimiento Nacional Búlgaro son moneda de uso común los términos "círculos culturales" (Igov 2001: 156) y "centros literarios" (o "centros culturales", "centros espirituales”) (Rádev 1997a: 394-396 y passim).

La gran mayoría de esos "centros" o "círculos" se encuentran fuera de las tierras búlgaras, o del inminente "Exarcado de Bulgaria" (1870), más fiable que las fronteras que se estipularon en el Congreso de Berlín de 1878, y están ligados a la actividad de uno o más "renacentistas". Como explica Rádev (1997a: 394):

Las condiciones políticas de los siglos XVIII y XIX condicionan también las formas de vida espiritual y literaria organizada. De hecho, en las fronteras etno-geográficas de la nacionalidad búlgara faltan las premisas y la atmósfera para la formación de centros de creación literaria y de edición [...]. ${ }^{1}$

Cronológicamente (siguiendo a Ígov 2001: 156-158, y a Rádev 1997a: 29, 41, 74, 88-89, 98-99, 394-398, 464-465, 774-776):

${ }^{1}$ La traducción es nuestra. 


\begin{tabular}{|c|c|c|c|c|}
\hline $\begin{array}{c}\text { Año } \\
\text { aproximado }\end{array}$ & Localidad & $\begin{array}{c}\text { Renacentistas más } \\
\text { notables }\end{array}$ & Publicaciones & $\begin{array}{c}\text { In stitu ciones } \\
\text { culturales }\end{array}$ \\
\hline 1820 & Braşov & $\begin{array}{c}\text { Pétar Berón, } \\
\text { Antón Jovánovič }\end{array}$ & $\begin{array}{c}\text { Abecedario del } \\
\text { Pez }\end{array}$ & $\begin{array}{l}\text { "Sociedad } \\
\text { Filológica } \\
\text { Búlgara" }\end{array}$ \\
\hline 1840 & Odessa & $\begin{array}{l}\text { Vasil Aprílov, } \\
\text { Najden Gérov, } \\
\text { Dobri Č́ntulov }\end{array}$ & & \\
\hline 1845 & Constantinopla & $\begin{array}{c}\text { Neófit Bózveli, } \\
\text { Petko R. Slavéjkov }\end{array}$ & $\begin{array}{c}\text { El periódico de } \\
\text { Constantinopla, } \\
\text { Macedonia, } \\
\text { Gaita }\end{array}$ & \\
\hline 1850 & Atenas & $\begin{array}{c}\text { Grigor Parlíčev, } \\
\text { Georgi S. Rakovski }\end{array}$ & $\begin{array}{l}\text { O Harmatolós, } \\
\text { Skender bey }\end{array}$ & $\begin{array}{c}\text { "Sociedad } \\
\text { Estudiosa } \\
\text { Eslavobúlgara", } \\
\text { "Sociedad } \\
\text { Macedonia" }\end{array}$ \\
\hline 1859 & Bolgrado & Dimítar Mútev & Labor Común & $\begin{array}{l}\text { "Escuela Central } \\
\text { Búlgara" } \\
\end{array}$ \\
\hline 1859 & Moscú & $\begin{array}{l}\text { Ljuben Karavélov, } \\
\text { Konstantín } \\
\text { Miladínov, } \\
\text { Rajko Žinzifov, } \\
\text { Nešo Bónčev, } \\
\text { Vasilaki Popóvič }\end{array}$ & $\begin{array}{c}\text { Labor Fraternal, } \\
15 \text { libros }\end{array}$ & $\begin{array}{l}\text { "Compañía } \\
\text { Búlgara" }\end{array}$ \\
\hline 1860 & Belgrado & $\begin{array}{c}\text { Georgi S. } \\
\text { Rakovski, Ljuben } \\
\text { Karavélov }\end{array}$ & $\begin{array}{c}\text { Cisne } \\
\text { Danubiano }\end{array}$ & \\
\hline 1861 & Brăila & $\begin{array}{l}\text { Dobri Vójnikov, } \\
\text { Vasil Drúmev, } \\
\text { Hristo Bótev }\end{array}$ & $\begin{array}{l}21 \text { periódicos y } \\
\text { revistas búlgaros }\end{array}$ & $\begin{array}{l}\text { Escuela búlgara, } \\
\text { "Sociedad } \\
\text { Filharmónica } \\
\text { Musa", "Sociedad } \\
\text { Literaria Búlgara" }\end{array}$ \\
\hline 1869 & Bucarest & $\begin{array}{c}\text { Georgi S. } \\
\text { Rakovski, Ljuben } \\
\text { Karavélov, Hristo } \\
\text { Bótev }\end{array}$ & $\begin{array}{l}\text { Futuro, Libertad, } \\
\text { Independencia, } \\
\text { Patria }\end{array}$ & $\begin{array}{l}\text { "Compañía } \\
\text { Virtuosa"* }\end{array}$ \\
\hline
\end{tabular}

También en los Principados Danubianos tuvo su papel, menos notable, la ciudad de Galapi, así como las dos capitales de Austria-Hungría, Viena y Budapest, sobre todo como centros universitarios y editoriales; Novi Sad en la década de 1850, como centro editorial en relación con G. S. Rakovski, y en fechas muy tempranas (décadas de 1830-1840) la minorasiática Esmirna, sede de una escuela búlgara y centro editorial (Rádev 1997a: 681-682).

2. Iván Rádev (n. 1943) nos ofrece interesantes observaciones sobre la "experiencia extranjera y los niveles de su adaptividad" de los "renacentistas búlgaros", observaciones que nos serán de gran utilidad para los exilios del siglo XX. Intenta distinguir entre dos "grupos"; unos, como 
Bótev, Karavélov, Stambolov, Vójnikov, Drúmev, sencillamente son parte de la emigración búlgara, y lo creado por ellos está enteramente dentro de lo orgánico del espacio estético nacional. El problema surge en aquellos para los que el medio extranjero también es "tema", también es alternativa, también es tentación, también es parte de la esencia de su camino. (Rádev 1997b: 255) ${ }^{2}$

Rádev escoge a tres representantes, en distinto grado, de esa "adaptividad", los tres del llamado "Renacimiento tardío" (1860-1870), con un rasgo en común: el bilingüismo. (Y en un caso, añadimos nosotros, el trilingüismo) (Rádev 1997b: 255263).

Al igual que otros "muchos búlgaros, formados en las tradiciones de culturas extranjeras, escriben en lengua no-materna: griego, serbio, francés, rumano, ruso, croata, e incluso latín" (Ígov 1995: 162), Grigor Pãrlíèev (Ócrida 1830-1993), Rajko žinzífov (Veles 1839-Moscú 1877) y Dimítãr Veliksín (Brãila 1840-París 1896), cuando se sirven de la lengua del medio en que se han formado o vivido, se manifiestan como poetas, pero la "migración de lengua" no se produce en ellos como en otros autores, búlgaros, de los siglos XX y XXI.

Pãrlíèev, por ejemplo, escribe sus dos epopeyas exclusivamente en griego; usa el búlgaro para la prosa documental, su autobiografía. žnzífov resuelve salomónicamente su "desdoblamiento", escribiendo poesía en búlgaro y publicística en ruso. Veliksín parece gozar de una decisión artística: escribe poesía ya en búlgaro, ya en francés, ya en rumano, conforme a estímulos internos.

3. No podemos dejar de mencionar la relación del patriarca de la literatura búlgara, Iván Vázov (1850-1921) con la literatura búlgara del exilio. Y ello en dos aspectos: su novela corta Немили-недраги (1883, Desventurados), una de las obras más apreciadas de toda la creación literaria de Vázov, refleja con realismo documental, pero también con gran carga de lirismo, la vida de la emigración búlgara en Rumanía, que incluye al personaje de Brãèkov, cuyo prototipo, sin llegar al autobiografismo, es el propio Vázov, y en general el escritor o poeta en el exilio rumano.

Desventurados, que fue escrita en el fructífero período de Plóvdiv, en la capital de la Rumelia Oriental autónoma, en vísperas de la unificación, rememora el exilio juvenil de Vázov en la Rumanía danubiana. Pero ese no fue el único período de exilio de Vázov: entre 1886 y 1888 abandona Bulgaria por la presión al partido rusófilo, y se instala, tras varios meses en Constantinopla, en Odessa. Allí escribiría la primera novela búlgara, Bajo el yugo; tanto en la primera como en sucesivas ediciones repetirá al final de ella "Odessa, 1888", aunque en realidad ello sea sólo estrictamente válido para la edición de Sofía, en tres entregas, entre 1889-1890. Con ello Vázov quería hacer hincapié en la exulitas de su creación, que verbalizó en el prefacio a la quinta edición de Bajo el yugo, la última que vio en vida, escrito el 19 de octubre de 1920, unos meses antes de su muerte, y que nos puede servir de textoguía para la creación literaria en el marco del exilio pre-moderno:

2 La traducción es nuestra. 
Estoy ante la quinta edición de Bajo el yugo. Quiero decir dos palabras ansiosas de ser dichas hace tiempo.

Desterrado de Bulgaria en 1887, pasé alrededor de un año en Odessa. Mucha aflicción, muchas penas experimentaba allí por la patria perdida. Mi mente, mi corazón, mi alma constantemente volaban hacia ella. Pero he aquí que me vino la inspiración para escribir esta novela y volví a respirar el aire de Bulgaria. Miles de recuerdos revivieron, miles de cuadros, brillantes y hermosos, cautivaron mi mirada intelectual, cuadros de la vida tormentosa de la patria durante la Insurrección de Abril.

¡Oh, visiones, cómo endulzabais mi alma! ¡Oh, días fatales, qué estremecimientos despertabais en ella! Olvidé las penas del destierro. Era feliz bañándome en las olas de los caros e inolvidables recuerdos, que me entusiasmaban, me dieron nuevo impulso y nueva juventud a mi musa, y desde el pobre cuartito de la apartada calle de Odessa mi libro recorrió toda Bulgaria, cruzó sus fronteras e irrumpió por Europa.

Y yo bendigo ahora ese destierro. (Vázov 1986: 436) ${ }^{3}$

\section{EL SIGLO XX Y SUS EXILIOS}

El siglo XX es el siglo de los exilios sudeslavos. Los cambios geopolíticos que afectan al Sur eslavo, la refección de sus Imperios en Estados de dudosa viabilidad, como se ha visto en el curso del propio siglo, las crisis económicas de viejo o de nuevo cuño, el desmoronamiento de los regímenes comunistas y las guerras subsiguientes, han provocado oleadas de exilios y emigraciones, entendidas habitualmente como, respectivamente, por motivos políticos o por motivos económicos.

La distinción terminológica no es casual. Puede llegar a proscribirse uno de los términos para evitar las connotaciones correspondientes: es el caso, por ejemplo, del término "diáspora", promocionado o evitado según por qué sectores de la un tiempo influyente emigración (éste sería el término más neutral) croata.

El siglo XX, como siglo de la globalización, ha provocado también, de una manera más sintomática que en los ejemplos sueltos e itinerantes del Renacimiento Nacional Búlgaro tardío, el fenómeno de la migración de lengua, que va ligado al concepto de "lengua de prestigio" y al fenómeno de los best-sellers literarios.

\subsection{Exilios bélicos y postbélicos. Exilios políticos y económicos}

1. En los comienzos de siglo, hasta los años anteriores a la Gran Guerra europea, gran número de súbditos de la monarquía austro-húngara emigra a las Américas.

Es interesante que, entre los emigrantes eslovenos a los Estados Unidos, los primeros, a principios de siglo, llegados como niños, cultivaron la literatura en lengua

\footnotetext{
3 La traducción es nuestra.
} 
eslovena. Son los casos de Ivan Molek (1882-1962), llegado a los Estados Unidos a los ocho años, que empezó a colaborar con publicaciones de la emigración eslovena y escribió sobre la vida de los emigrantes, ya teatro: Slepci (Ciegos, 1921), Na drugi fronti (En otro frente, 1923), Miši (Ratones, 1938); ya novela, como la trilogía Dva svetova (Dos mundos, Ljubljana 1933), Veliko mravljišèe (El gran hormiguero, 1934) y Sesuti stolp (Torre derrumbada, 1935).

Tal como Molek, que tradujo del inglés al esloveno, Ivan Zorman (1899-1958) es el primer traductor importante de poesía eslovena al inglés. Llegado a los Estados Unidos a los cuatro años, empezó a publicar poesía en esloveno en 1916 en las publicaciones de la numerosa emigración eslovena de Cleveland. Además de componer música, publicó los poemarios Poezije (Poesías, 1919), Pesmi (Poemas, 1922), Lirièni spevi (Cantos líricos, 1925), Pota ljubezni (Caminos del amor, 1931) e Iz novega sveta (Del nuevo mundo, 1938). Zorman es un poeta lírico, raro cultivador de lo social, a diferencia de Molek, de ideas socialistas.

El nombre más destacado de la "literatura eslovena en los EE.UU." (Janež 1959: 435) es Alojz Adamiè, o Louis Adamic (1898-1951). Emigrado con quince años, participó en la I Guerra Mundial como soldado de los EE.UU. en el frente francoalemán. A pesar de ser el más adulto de los autores que hemos citado, Louis Adamic escribió sólo en inglés, su lengua de adopción. También tradujo al inglés literatura eslovena, croata y serbia.

Empezó a publicar en 1928 en The American Mercury. Sus novelas, libros de viajes, tratados ensayísticos, a menudo de carácter autobiográfico, tratan de sus dos patrias, a menudo ocupándose de temas sociales. Fueron muy populares y se tradujeron a lenguas varias, incluidas las de Yugoslavia: Dynamite: The Story of Class Violence in America 1830-1934 (1931), Laughing in the Jungle: The Autobiography of an Immigrant in America (1932), Grandsons: A Story of American Lives (1935), Cradle of Life: The story of One Man's Beginnings (1937), The House in Antigua: A Restoration (1938), My America: 1928-1938 (1938), From Many Lands (1939), My Native Land (1943), Dinner at the White-House (1946), A Nation Of Nations (1948).

Tuvo ocasión de visitar su tierra natal en dos ocasiones, cada una de las cuales le dio motivo para escribir un libro: The Native's Return: An American Immigrant Visits Yugoslavia and Discovers His Old Country (1934) y The Eagle and the Roots (1952).

2. Ya desde principios de los años veinte del siglo XX se produce una importante emigración de Bulgaria a América del Sur, principalmente a la Argentina y al Brasil. Los motivos de esa emigración fueron, fundamentalmente, económicos, aunque en algunos casos es perceptible cierto aventurerismo.

Es un tema aún insuficientemente estudiado por la historiografía literaria búlgara (Nikólov 2010). En cierto modo es explicable: los escritores ligados a esa experiencia hispanoamericana son, muchas veces, menores, o sólo aportan el exotismo de sus narraciones a su vuelta a la patria.

Éste es el caso del más apreciado de entre ellos, Borís Šiváèev (1902-1932), 1lamado el "Jack London búlgaro", residente en la Argentina entre 1920 y 1924, que publicó en Bulgaria Сръберната река (El río de la Plata, 1926) у Писма от Южна Америка (Cartas de Sudamérica, 1932). 
Otros autores con experiencia iberoamericana son Matvej Vằlev (1902-1944), estudiante en Alemania (1923-1930) y trabajador en Sudamérica (1931-1934), cuya experiencia trasladó a sus libros de cuentos Прax cıedcmadama (Polvo tras las manadas, 1937) у Отсам и отвъd De acá y de más allá, 1940), al igual que Iván Aržentinski (1910-1989), quien, además del pseudónimo, de su estancia en la Argentina entre 1930 у 1934 sacó los materiales para su libro Аалечна Патагония (Lejana Patagonia, 1947).

No obstante, también encontramos autores como Samuil D. Strézov (19011984), nacido en Sofía, pero que residió desde 1920 en la Argentina, donde publicó su novela autobiográfica en español Anga (1929). Tódor Cénkov (1903-1987) vivió en la Argentina en 1921-1924 y 1936-1947, y en Buenos Aires publicó, en búlgaro, su novela Великия океан (El gran осе́апо, 1938).

Stefan M. Kínchev (1895-1985), búlgaro de Besarabia, emigró a Brasil a los 31 años y allí publicó su novela autobiográfica en portugués Estranha idéia de um moço (3 volúmenes, Paraná 1960).

Una figura singular, paralela de algún modo a la de Louis Adamic, es la de Stoján Hrístov, conocido con la grafía de Stoyan Christowe (1898-1995), nacido en una aldea búlgara de la comarca de Salónica, llegado a los EE.UU. en 1911, corresponsal de prensa del Chicago Daily News en los Balcanes desde mediados de los años veinte, incurso en la vida política de Vermont desde 1944, atraído por el macedonismo postbélico titista (viajó a Yugoslavia en 1980).

$\mathrm{Su}$ obra literaria trata de temas balcánicos y patrióticos de los EE.UU.: Heroes and Assasins (1935), Mara (1937, traducido al búlgaro y publicado en Sofía en 1942 con el título de Една българка , "Una búlgara"), This is my country: an autobiography (1938), The Lion of Yanina (1941), My American Pilgrimage (1947), The Eagle and The Stork (1976).

3. La II Guerra Mundial fue un factor de inestabilidad y peligro en todos los Balcanes, y en general en todos los países eslavos meridionales, y su fin y la instalación de los nuevos regímenes el origen de un cataclismo.

Entre los búlgaros se da un caso bastante específico, el de Kosta Tódorov (Moscú 1889-París 1947), participante en el gobierno de la Unión Agraria y diplomático, que fue expulsado por el régimen unipersonal del zar Borís III, y publicó su novela autobiográfica en inglés Balkan Firebrand: The Autobiography of a Rebel, Soldier and Statesman en Chicago-New York en 1943.

En cambio, Stefan Grúev o Stéphane Groueff (Sofía 1922-Nueva York 2006), hijo del jefe del gabinete del zar Borís III, ejecutado en 1944, no volvió a Bulgaria tras el cambio de régimen, pasando a Francia en 1947 y a los EE.UU. en 1957. Muy reconocido como búlgaro en la emigración, publicó en francés e inglés, por ejemplo, Manhattan Project: The Untold Story of the Making of the Atomic Bomb (1967), L'homme et la terre (1977), L'homme et le cosmos (1978), Crown of Thorns (1987), sobre el reinado del zar Borís III, o su autobiografía My Odyssey (2003).

La emigración sudeslava de la I Yugoslavia o de sus estados herederos durante la II Guerra Mundial tuvo especial vinculación con el mundo hispánico, sobre todo con Sudamérica, pero también con España, y no sólo en el círculo de los estudiantes del Colegio Mayor "Santiago Apóstol" de Madrid. 
Los eslovenos (Kos 1992: 381-382 y 400-401) radicaron principalmente en la Argentina, donde ya existía una nutrida colonia de emigrantes. Entre los mayores está el poeta Tine Debeljak (1903-1989), autor de, entre otros, el extenso poema Velika èrna maša za pobite Slovence (Gran misa negra por los eslovenos asesinados, 1949), y editor que fue de las poesías de France Balantiè (1921-1943), quemado vivo en lucha con los guerrilleros, con el título V ognju groze plapolam (En el fuego del horror flameo, 1944).

Zorko Simèiè (Maribor 1921) volvió a Eslovenia en 1994, después de huir a Austria en 1945 y, tras un período en Italia, vivir en Buenos Aires y Bariloche. Ha cultivado todos los géneros literarios y dirigido revistas literarias, y su novela Ėlovek na obeh straneh stene (Hombre a ambos lados del muro, 1957) se tiene por una de las mejores de la literatura postbélica, en la línea existencialista característica de la novelística eslovena.

En la emigración del Estado Independiente de Croacia, Viktor Vida (Kotor 1913Buenos Aires 1960) emigró a la Argentina en 1948 desde Italia, donde se encontraba desde 1942. Considerado uno de los mejores poetas croatas emigrados, con cuyas publicaciones colaboraba activamente, publicó sus poemarios en Buenos Aires, Svemir osobe (Universo de la persona, 1951) y Sužanj vremena (Cautivo del tiempo, 1956), antes de su suicidio.

La figura del arzobispo católico de Sarajevo Dr. Ivan Ev. Šariæ (Travnik 1871Madrid 1960) a veces se polemiza por su papel -como el de la Iglesia Católica en general- en el Estado Independiente de Croacia; en 1945 se estableció en España, donde publicó poemarios como Vrata Sunca (Puerta del Sol, 1953) o ensayos como Svet Franjo Asiški i Sveti Franjo Ksaverski (San Francisco de Asís y San Francisco Javier, 1953), pero adquirió celebridad y estimación literaria por su traducción croata de la Biblia, cuya segunda edición corregida apareció en Madrid en 1959.

El diplomático y poeta modernista serbio Jovan Duèiæ (Trebinje 1871-Gary, Indiana 1943) huyó a los EE.UU. en 1941. Allí publicó algunos escritos políticos, así como su Lirika (Lírica, Pittsburgo 1943) en su propia edición.

4. La década de 1960, como tenemos ocasión de comprobar, puede considerarse la transición entre los viejos y los nuevos exilios del siglo XX.

Si en 1960 mueren Vida y Šariæ, ese mismo año huyen los hermanos Maruna a Italia. De ellos, Boris Maruna (1940-2007), residente después en la Argentina, Gran Bretaña, los EE.UU., para regresar después de la independencia de Croacia a su tierra, representa una renovación en la poesía croata: Vida fue autor "italianista", Maruna admira a Charles Bukowski o Nicanor Parra, y publica su primer poemario en Buenos Aires: I poslije nas ostaje ljubav ( $Y$ después de nosotros queda el amor, 1964).

El esloveno Lev Detela (Maribor 1939) también huyó de Yugoslavia en 1960, a Austria, donde siguió estudiando y empezó a escribir poesía, prosa, teatro, ensayo, tanto en esloveno como en alemán. Prohibido en Eslovenia hasta 1990, considerado un disidente, ha publicado su extensa producción en Viena, Trieste, Klagenfurt, Londres.

El caso del disidente búlgaro Georgi Márkov (Knjáževo, Sofía 1929-Londres 1978) fue bastante diferente. Escritor y dramaturgo de éxito en la República Popu- 
lar de Bulgaria, sus problemas de censura le hicieron viajar a Italia en 1969, por un tiempo, pero en 1971 se trasladó a Gran Bretaña, donde trabajó para las emisiones de la BBC, Radio Free Europe, Deutsche Welle, hasta su asesinato por la Seguridad del Estado búlgara. Empezó a escribir en inglés (su obra de teatro Archangel Michael ganó el primer premio en el Festival de Edimburgo de 1974), aunque parece evidente que sus Задочни репортажи за България (Reportajes a distancia sobre Bulgaria, 1975-1978, publicados póstumamente en Zürich en 1981-1982) provocaron su sentencia de muerte.

Dos búlgaros se han destacado en Francia y Europa Occidental como ensayistas y escritores en francés: Cvetán Tódorov o Tzvétan Todorov (Sofía 1939) y Júlija Krằsteva o Julia Kristeva (Sliven 1941), que marcharon a París para continuar estudios en 1963 y 1965, respectivamente, y allí siguieron su carrera profesional. Son casos bastante especiales, poco comparables con los anteriores, salvo en lo cronológico, como puede comprobarse con la lectura de L'homme dépaysé (1996) de Cv. Tódorov.

\subsection{Exilio y best-seller}

Uno de los autores más estimados y traducidos de la literatura serbia, Danilo Kiš (Subotica 1939-París 1989) transcurrió períodos de su vida en distintas ciudades francesas como "lector de serbocroata", y a esos períodos se vinculan partes de su creación literaria; pero hasta octubre de 1979 no decide el "exilio elegido" (izabrano izgnanstvo) de París.

Kiš es quizá el último de los exilados o disidentes de los antiguos regímenes del Sur eslavo. Los ulteriores, salvo alguna excepción, están vinculados a las guerras de Yugoslavia de la última década del siglo XX. Y, aunque no es una regla general, muchos de ellos comparten la característica de la disidencia y el exilio con el éxito editorial, también internacional en el plano de las traducciones y ediciones en el extranjero.

Hay un grupo de autores búlgaros que, instalados en el exterior de su patria, escriben en alemán, como Ilija Trojanow (Sofía 1965), especie de "epígono" de los disidentes de los años sesenta, pues huyó con su familia a Alemania en 1971, y después de vagar por el mundo, hoy en un autor estimado, vendido y traducido de lengua alemana, con novelas como Die Welt ist gross und die Rettung lauert überall (1996) o Der Weltensammler (2006), o Dimitré Dinev (Dimítãr Dínev, Plóvdiv 1968), que se instaló en Austria en plena "transición" búlgara, en 1990, y publica en alemán novelas como Engelszungen (2003) o cuentos como los de Ein Licht über dem Kopf (2005). Zahari o Zack Karábashliev (Varna 1968) se mudó a los EE.UU. en 1997 y, aunque escribe tanto en búlgaro como en inglés, en su lengua materna ha tenido los mayores logros y éxitos, como la novela $18 \%$ сиво (18\% gris, 2008) о los cuentos de Кратка история на самолета (Breve historia del avión, 2010); también recibe galardones por su teatro.

Las guerras y las postguerras yugoslavas han sido dramáticamente fructíferas en exilios: Dubravka Ugrešiæ (Zagreb 1949) abandonó la Croacia ya independiente en 
1993 por una "caza de brujas" anti-feminista, y hoy vive en Ámsterdam. Ya bestseller en el período anterior, con repercusión y traducciones internacionales, ha literaturizado la experiencia del exilio en los cuentos de Muzej bezuvjetne predaje (El museo de la rendición incondicional, 1998) o Ministarstvo boli (El ministerio del dolor, 2004).

De los autores de la literatura serbia citaremos tres nombres: Stevan Tontiæ (Sanski Most, BiH 1946) salvó su vida huyendo ilegalmente del cerco de Sarajevo en invierno de 1993, y vivió en el exilio alemán hasta finales de 2001: dos poemarios Sarajevski rukopis (Manuscrito de Sarajevo, 1993) y Blagoslov izganstva (La bendición del exilio, 2001) marcan el antes y el después de ese período, que el propio autor veía "sin final".

David Albahari (Peæ, Kosovo 1948) se instaló en Calgary, Canadá, en el otoño de 1994. Narrador ya consagrado, no obstante, ha obtenido sus mayores repercusiones en el exilo: Mamac (El anzuelo, 1996) y Gec i Majer (Götz y Meyer, 1998).

Bora Æosiæ (Zagreb 1932) vivió en Belgrado desde los cinco años. Su novela satírica Uloga moje porodice u svetskoj revoluciji (El papel de mi familia en la revolución mundial, 1970) le trajo problemas en Yugoslavia y éxito, al cabo de décadas, en el extranjero. En 1992 se fue a vivir a Istria y en 1995 a Alemania: "Nadie me echó de Serbia, pero en los noventa sentí el olor del fascismo. Cogí la maleta y me fui". En la fase istriana publicó su Dnevnik apatrida (Diario de un apátrida, 1993), y en 2002 la novela de significativo título Nulta zemlja (Tierra cero).

Sólo dos casos de "migración de lengua": el croata Josip Novakovich (Daruvar 1956) se instaló en los EE.UU., donde ya había vivido su familia, en 1976. Escribe sólo en inglés y su novela de ambiente bélico croata April Fool's Day (2006) ha tenido cierta repercusión, quizá coyuntural.

El caso de Aleksandar Hemon (Sarajevo 1964) es más peculiar: en 1992 se encontraba en Chicago y decidió no regresar a Bosnia. Aunque también escribe en su lengua materna, el inglés aprendido por la fuerza de las circunstancias lo ha convertido en un narrador de éxito internacional, con los cuentos The Question of Bruno (2000) o las novelas Nowhere Man (2002) y The Lazarus Project (2008).

\section{CONCLUSIONES}

El estudio comparado de las literaturas eslavas, especialmente las del Sur, representa un campo enorme e inexplorado. Dificultades metodológicas aparte y de falta de ediciones críticas o modernas, el prejuicio político puede prevalecer, especialmente cuando se trata de disidencia y exilio.

Para poder hablar de litterae exules hay que partir del concepto de "literatura (y lengua) nacional" y, como vemos, sólo se produce desde que ella existe, en sus principios (Escuela Literaria de Tằrnovo, literatura protestante eslovena) o en sus restauraciones (Renacimiento Nacional Búlgaro, quizá algunos fenómenos contemporáneos).

Los siglos XX y XXI representan la "globalización” del exilio: las crisis y conflictos transnacionales provocan movimientos transnacionales, $\mathrm{y}$ el bagaje civiliza- 
cional de los "desplazados" comporta, a veces, la traducción del acerbo literario, o su expresión bilingüe.

\section{BIBLIOGRAFÍA}

GORTAN, Veljko; \& VRATOVIĆ, Vladimir (priredili diqesserunt [sic]) (1969): Hrvatski latinisti /Croatici auctores qui Latine scripserunt. I: Iz latiniteta 9-14. stoljeca. Pisci 15. i 16. stoljeca. / Ex monumentis Latinis saec. IX-XIV. Auctores saec. XV et XVI. Zagreb: Matica hrvatska/Zora.

GUILLÉN, Claudio (1998): "El sol de los desterrados: literatura y exilio", en Múltiples moradas: Ensayo de Literatura Comparada, pp. 29-97. Barcelona: Tusquets.

HGOV, Svetlozar (1995): Антология на българската поезия. Plyvdiv: ИзАателство "Христо Г. Аанов". Основано през 1855 г.

-(2001): История на българскаталитература. Sofна: Ciela Soft and Publishing.

JANEŽ, Stanko (1959): Istorija slovenacke knjiłevnosti. Prema drugom slovenačkom preradjenom izdanju u saradnji s Miroslavom Ravbarom. Sarajevo: Izdavačko preduzeće "Veselin Masleša".

JEŽIĆ, Slavko (1944): Hrvatska književnost od početka do danas: 1100-1941. Zagreb: Naklada A. Velzek.

KOS, Janko (1992): Pregled slovenskega slovstva. 10. popravljena in dopolnjena izdaja. Ljubljana: Drhavna zaloћba Slovenije.

NIKУLOV, Georgi N. (2010): Бъмгарски пера в чужбина. Пътеписи. Морски блянове. Аитературен свят. En: http://literaturensviat.com/?p=29351 [Consulta: enero de 2011].

PETKÁNOVA, Donka (съст.) (2003): Старобългарска митература: Енииклопедичен речник. Научни реАактори Иван Аобрев и Анисава Миятенова. Отоворен редактор Аонка Петканова. Второ преработено и допъмнено издание. Veliko Tằrnovo: ИзАателство "Абагар".

RÁDEV, Iván (отг. реА.) (1997a): Енциклопедия на българската възрожденска литература. Veliko T?rnovo: Изаателство "Абагар".

RБDEV, Iv6n (1997b): История на бъмгарската митература през Възраждането. Veliko Tằrnovo: ИзАатемство “Абагар".

VbZOV, Iv6n (1986): Под игото. Предговор Петър Аинеков. Приможение Галина Минчева. Sofна: ИзАателство Бъмгарски писател. 